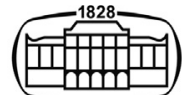

AKADÉMIAI KIADÓ

European Journal of Microbiology and Immunology

$11(2021)$ 4, 87-94

Dol:

$10.1556 / 1886.2021 .00022$

(c) 2021 The Author(s)

\section{ORIGINAL RESEARCH} PAPER

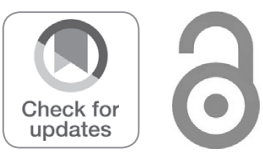

\title{
Inhibitory effects of specific combination of natural compounds against SARS-CoV-2 and its Alpha, Beta, Gamma, Delta, Kappa, and Mu variants
}

\author{
ANNA GOC, ALEKSANDRA NIEDZWIECKI* ${ }^{*}$, \\ VADIM IVANOV, SVETLANA IVANOVA and \\ MATTHIAS RATH
}

Dr. Rath Research Institute, 5941 Optical Ct., San Jose, CA 95138, USA

Received: November 30, 2021 • Accepted: December 20, 2021

Published online: January 21, 2022

\begin{abstract}
Despite vaccine availability, the global spread of COVID-19 continues, largely facilitated by emerging SARS-CoV-2 mutations. Our earlier research documented that a specific combination of plant-derived compounds can inhibit SARS-CoV-2 binding to its ACE2 receptor and controlling key cellular mechanisms of viral infectivity. In this study, we evaluated the efficacy of a defined mixture of plant extracts and micronutrients against original SARS-CoV-2 and its Alpha, Beta, Gamma, Delta, Kappa, and $\mathrm{Mu}$ variants. The composition containing vitamin $\mathrm{C}, \mathrm{N}$-acetylcysteine, resveratrol, theaflavin, curcumin, quercetin, naringenin, baicalin, and broccoli extract demonstrated a highest efficacy by inhibiting the receptor-binding domain (RBD) binding of SARS-CoV-2 to its cellular ACE2 receptor by $90 \%$. In vitro exposure of test pseudo-typed variants to this formula for $1 \mathrm{~h}$ before or simultaneously administrated to human pulmonary cells resulted in up to $60 \%$ inhibition in their cellular entry. Additionally, this composition significantly inhibited other cellular mechanisms of viral infectivity, including the activity of viral RdRp, furin, and cathepsin L. These findings demonstrate the efficacy of natural compounds against SARS-CoV-2 including its mutated forms through pleiotropic mechanisms. Our results imply that simultaneous inhibition of multiple mechanisms of viral infection of host cells could be an effective strategy to prevent SARS-CoV-2 infection.
\end{abstract}

\section{KEYWORDS}

SARS-CoV-2, variants, RdRp, furin, cathepsin L

\section{INTRODUCTION}

Despite availability of vaccines and drastic public health measures, the spread of SARS-CoV2 infection continues [1]. According to the WHO, as of August 31, 2021, there have been almost 217 million cases worldwide, resulting in more than 4.51 million deaths [2].

Within one year of the pandemic, several variants of SARS-CoV-2 virus have emerged including: United Kingdom B.1.1.7 (Alpha) variant, South Africa B.1.315 (Beta), Brazil P.1 (Gamma), and mutated forms from India known as lineage B.1.617.1 (Kappa) and B.1.617.2 (Delta) [3]. All of these variants spread to other countries, with each mutation potentially giving rise to further variants such as originated in Japan R.1 variant having a mutation E484K located in the spike protein giving "increased resistance" to antibodies generated by the current vaccines [4], as well as a D614G mutation giving increased infectiousness and present in all other variants that have surpassed the Alpha strain [5]. Clinical reports also show that the British variant can infect patients, who have received the vaccine developed against the original SARS-CoV-2, thereby challenging any claim of its universal efficacy [6].

Corresponding author. Dr. Rath +14085675050.

E-mail: author@drrath.com 
There are recent indications that the newly emerged $\mathrm{Mu}$ variant and R.1 variant may escape antibodies generated by the application of vaccines against original SARS-CoV-2 [7]. Thus, it is foreseeable that the ultimate control of the ongoing COVID-19 pandemic caused by the rapidly emerging mutations of SARS-CoV-2 will be compromised by the need to develop new vaccines potentially for every new variant, and by the related scientific, economic, and social consequences of such a strategy.

The cellular entry mechanism of SARS-CoV-2 has been extensively studied and found to be mediated by a spike protein anchored on the surface of the virus. The spike protein is a trimer, with three receptor-binding S1 heads sitting on top of a trimeric membrane fusion S2 stalk [8]. The spike S1 protein on SARS-CoV-2 contains a receptorbinding domain (RBD) that binds to a target cell using the human ACE2 (hACE2) receptor present on the surface of many types of cells and is proteolytically activated by human proteases. Entry into host cells is an important determinant of viral infectivity and pathogenesis [9-11].

Cellular infection by the SARS-CoV-2 is facilitated by several host enzymatic proteins, including transmembrane protease serine 2 (TMPRSS2), furin, cathepsin L, as well as RNA-dependent RNA polymerase (RdRp) catalyzing viral RNA multiplication [12]. The RNA-dependent RNA polymerase (RdRP) is a conservative in the structure viral enzyme with no host cell homologs and as such it has been of interest in developing selective inhibitors as a potentially safer alternative for treating COVID-19 and not affecting human host cells proteins directly [13].

Application of natural compounds with their wide pleiotropic effects provides an opportunity of controlling several mechanisms associated with SARS-CoV-2 infection with a high margin of safety. Since the emergence of COVID-19, several studies have shown the efficacy of such compounds as inhibitors [14-17]. Our earlier studies also identified the efficacy of plant-derived compounds on several cellular mechanisms of SARS-CoV-2 infectivity [18-20]. In this study, we evaluated the efficacy of a specific combination of micronutrients and plant extracts against newly emerged mutated forms of SARS-CoV-2 and the activity of key enzymes involved in viral processing in human alveolar cells. This approach aims at simultaneous inhibition of multiple cellular mechanisms involved in SARS-CoV-2 infectivity, irrespective of mutation and/or subtype, thereby opening new avenues towards the global control of the pandemic.

\section{MATERIALS AND METHODS}

\section{Cell lines, virial particles, and antibodies}

A549 and VeroE6 cells were obtained from American Type Culture Collection (Manassas, VA, USA). The hACE2/A549 cells (i.e., A549 cells stably overexpressing human ACE2 receptor) and eGFP-luciferase-SARS-CoV-2 spike protein encapsulated pseudo-typed particles were purchased from GenScript (Piscataway, NJ, USA). Pseudo-typed $\Delta$ G-luciferase
(G* $\Delta$ G-luciferase) rVSV was obtained from Kerafast (Boston, MA, USA). Alpha, Beta, Gamma, Delta, Kappa, Mu, and bald eGFP-luciferase-SARS-CoV-2 pseudo-typed particles were from BPS Bioscience (San Diego, CA, USA). All other compounds were from Sigma (St. Louis, MO, USA) except for broccoli extract that was from Bulk Supplements (Henderson, NV, USA).

\section{Plant-derived compositions}

The combinations of natural compounds tested in this study are presented in Table 1. Stock solutions of these combinations were prepared in dimethylsulfoxide (DMSO) at $50 \mathrm{mg} \mathrm{mL}^{-1}$ and kept at $-20^{\circ} \mathrm{C}$ until analysis. For the experiments, the stock solution was diluted with $1 \times$ phosphate buffered saline $(1 \times$ PBS $)$ or a buffer recommended by the manufacturer of the utilized kit (enzyme activity assays) or corresponding cell culture medium (cell-based experiments) to final concentrations indicated in the Figures.

\section{Binding of SARS-CoV-2 pseudo-typed virions to hACE2 receptor}

The experiment followed our previously published methodology $[18,19]$. Briefly, original eGFP-luciferase-SARS-CoV-2 spike protein encapsulated pseudo-virion or its variants were incubated at $37^{\circ} \mathrm{C}$ with $0-100 \mu \mathrm{g} \mathrm{mL} \mathrm{L}^{-1}$ of MixV for either $1 \mathrm{~h}$ before it was added into a monolayer of hACE2/A549 cells or added simultaneously to hACE2/A549 cells. Cells were incubated for an additional $48 \mathrm{~h}$ at $37^{\circ} \mathrm{C}$. After the 48 -h incubation period, the transduction efficiency was quantified by recording the luciferase activity, utilizing a luciferase assay system (Promega, Madison, WI, USA) and a spectrofluorometer (Tecan Group Ltd., Männedorf, Switzerland). The positive control was bald eGFP-luciferase-SARS-CoV-2 pseudo-typed particles, and the negative control was $\Delta$ G-luciferase rVSV pseudo-typed particles. Data are presented as a \% of control without Mix-V addition (mean \pm standard deviation (SD), $n=5)$.

\section{In vitro $\mathrm{RdRp}$ activity assay}

In vitro RdRp activity was evaluated using a SARS-CoV-2 RNA Polymerase Assay Kit (ProFoldin, Hudson, MA, USA)

Table 1. Combinations of plant extracts and micronutrients tested in the study

\begin{tabular}{lccccc}
\hline Substance & MixA & MixB & MixC & MixV & MixE \\
\hline Green tea extract & + & + & + & & \\
Resveratrol & + & + & + & + & + \\
Broccoli extract & + & + & + & + & + \\
Curcumin & + & + & + & + & + \\
Quercetin & + & + & + & + & + \\
Naringenin & + & + & + & + & + \\
Baicalin & + & + & + & + & + \\
Theaflavin & + & & & + & + \\
Vitamin C & + & + & + & + & + \\
N-acetylcysteine & & + & & + & \\
Fucoidan & & & + & & + \\
\hline
\end{tabular}


according to the manufacturer's protocol. Briefly, $0.5 \mu \mathrm{L}$ of $50 \times$ recombinant $\mathrm{RdRp}$ or $20 \mu \mathrm{L}$ of cell lysate [to transduce cells with eGFP-luciferase-SARS-CoV-2 RdRp lentivirus (GenScript, Piscataway, NJ, USA), VeroE6 cells were seeded into a 6-well plate in the presence of complete growth medium and treated with $8 \mu \mathrm{L} \mathrm{mL} \mathrm{mL}^{-1}$ polybrene (Sigma, St. Louis, MO, USA) for $30 \mathrm{~min}$, followed by the addition of eGFP-luciferase-SARS-CoV-2 RdRp lentivirus at multiplicity of infection $(\mathrm{MOI}=5)$ [our previous preliminary results showed an almost $100 \%$ transduction rate can be achieved with this MOI], and spin-inoculation at $1,000 \times \mathrm{g}$ for $1.5 \mathrm{~h}$. After $24 \mathrm{~h}$ at $37^{\circ} \mathrm{C}$ incubation, cells were fed with fresh complete growth medium. After $48 \mathrm{~h}$ post-inoculation, cells were detached with $1 \mathrm{mM}$ EDTA, washed three times with 1 $\times$ PBS supplemented with $3 \%$ fetal bovine serum (FBS)] was incubated with $2.5 \mu \mathrm{L}$ of $50 \times$ buffer, $20 \mu \mathrm{L}$ of water (only when recombinant RdRp enzyme was used), and $1.0 \mu \mathrm{L}$ of MixV at $0-100 \mu \mathrm{g} \mathrm{mL}^{-1}$ concentrations for $15 \mathrm{~min}$ at $\mathrm{RT}$, followed by the addition of the master mix containing $0.5 \mu \mathrm{L}$ of $50 \times$ NTPs and $0.5 \mu \mathrm{L}$ of $50 \times$ template (as a singlestranded polyribonucleotide). The reaction $(25 \mu \mathrm{L})$ was incubated for $2 \mathrm{~h}$ at $34^{\circ} \mathrm{C}$ and then stopped by the addition of $65 \mu \mathrm{L}$ of $10 \times$ fluorescence dye, and the fluorescence signal was recorded in $10 \mathrm{~min}$ at extension/emission $=488$ / $535 \mathrm{~nm}$ using a fluorescence spectrometer (Tecan, Group Ltd., Männedorf, Switzerland). Positive control contained $100 \mu \mathrm{g} \mathrm{mL}^{-1}$ remdesivir. Results are expressed as a \% of control without MixV addition (mean $\pm \mathrm{SD}, n=5$ ).

\section{Furin activity assay}

Effects of MixV on furin enzymatic activity were evaluated using a SensoLyte Rh110 Furin Activity Assay Kit (AnaSpec, Fremont, CA, USA) according to the manufacturer's protocol. Briefly, MixV at 5 and $10 \mu \mathrm{g} \mathrm{mL}^{-1}$ concentrations was mixed with furin recombinant protein for $15 \mathrm{~min}$, followed by the addition of fluorogenic Rh110 furin substrate. The samples were incubated for $1 \mathrm{~h}$ at $22^{\circ} \mathrm{C}$ and the fluorescence was recorded at extension/emission $=490 / 520 \mathrm{~nm}$ with a fluorescence spectrometer (Perseptive Biosystems Cytofluor 4000, Framingham, MA, USA). Positive control as a peptidyl chloromethylketone (Decanoyl-Arg-Val-Lys-Arg-CMK) contained $0.1 \mu \mathrm{M}$. Data are presented as a $\%$ of control without MixV addition (mean $\pm \mathrm{SD}, n=5$ ).

\section{Cathepsin L activity assay}

Effect of MixV on the activity of recombinant cathepsin L was evaluated using a Cathepsin L Activity Screening Assay Kit (BPS Bioscience, San Diego, CA, USA), according to the manufacturer's protocol. Briefly, MixV at 5 and $10 \mu \mathrm{g} \mathrm{mL}^{-1}$ concentrations was added to cathepsin $\mathrm{L}(0.2 \mathrm{mU} / \mu \mathrm{L})$ for $15 \mathrm{~min}$ at $22^{\circ} \mathrm{C}$ prior to fluorogenic substrate (Ac-FR-AFC) $(10 \mu \mathrm{M})$ addition and incubation for further $60 \mathrm{~min}$ at RT. Positive control contained only cathepsin L, and negative control contained cathepsin $\mathrm{L}$ and cathepsin L inhibitor E$64(25 \mu \mathrm{M})$. The fluorescence was recorded at extension/ emission $=360 / 480 \mathrm{~nm}$ with a fluorescence spectrometer (Tecan Group Ltd., Männedorf, Switzerland). Data are presented as a percentage of control without MixV addition (mean $\pm \mathrm{SD}, n=5$ ).

\section{Viability}

Cell viability assay was performed using MTT substrate. Briefly, $40 \times 10^{3}$ A549 cells per well were treated with different concentrations of MixV alone or in combination with vitamin D and zinc for up to $48 \mathrm{~h}$. Subsequently, the wells were washed with $1 \times$ PBS and complete growth medium supplemented with $5 \mathrm{mg} \mathrm{mL}^{-1}$ MTT was added, followed by incubation for $4 \mathrm{~h}$ at $37^{\circ} \mathrm{C}$. Next, the culture medium was aspirated and $100 \mu \mathrm{L}$ of methanol was added. The absorbance was assessed at $570 \mathrm{~nm}$ with a fluorescence spectrometer (Molecular Devices, San Jose, CA, USA). Data are presented as a $\%$ of control without MixV addition (mean $\pm \mathrm{SD}, n=8$ ).

\section{Statistical analysis}

Data for all experiments are presented as an average value and standard deviation from at least three independent experiments. Comparison between different samples was done by a two-tailed T-test using the Microsoft Office Excel program. Differences between samples were considered significant at $P$ values less than 0.05 .

\section{Ethics}

No human subjects were involved in this study. Therefore IRB ethical approval and informed consent are not applicable.

\section{RESULTS}

\section{Selection of the most effective composition of natural compounds based on its inhibition of viral RBD binding to hACE2 receptor}

The results in Fig. 1 show the efficacy of various combinations of plant extracts and micronutrients on inhibition of SARS-CoV-2 RBD binding to epithelial pulmonary cells over-expressing human ACE2 receptor. All five compositions displayed inhibitory effects on RBD binding at the level of $50 \%$ and higher. The highest inhibition, i.e., by $90 \%$ compared to control, was obtained with MixV applied at $10 \mu \mathrm{g} \mathrm{mL}^{-1}$ concentration (Fig. 1A). The addition of vitamin $\mathrm{D}$ or zinc to MixV did not further enhance the inhibition of $\mathrm{RBD}$ binding to human ACE2 receptor as shown in Fig. $1 \mathrm{~B}$.

\section{Effect of MixV on cellular attachment and entry of SARS-CoV-2 and its pseudo-typed variants}

The effect of different pattern of applications of MixV on the attachment and cellular entry of eGFP-luc-spike-enveloped pseudo-typed variants was tested using A549/hACE2 cells. The results presented in Fig. 2A show that the exposure of pseudo-virions to MixV before their infection of human lung cells was effective in decreasing cellular entry of all tested SARS-CoV-2 variants. As such, the MixV applied at $10 \mu \mathrm{g} \mathrm{mL}^{-1}$ to original SARS-CoV-2 strain and its Alpha, 

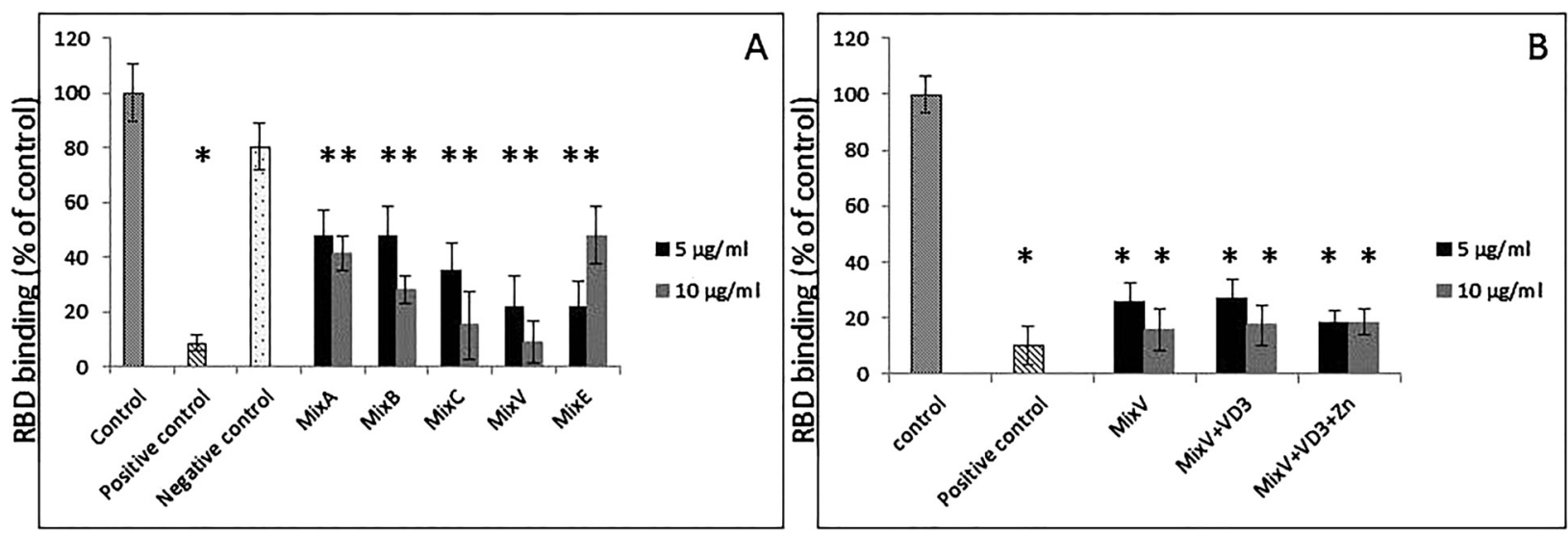

Fig. 1. Effect of test compositions on SARS-CoV-2 RBD-spike protein attachment to lung epithelial cells. Inhibitory effect of Mixes A, B, C, V, and $\mathrm{E}$ on viral SARS-CoV-2 RBD binding to human ACE2 receptor (A). Inhibitory effect of MixV in the presence of vitamin D and zinc on viral SARS-CoV-2 RBD binding to human ACE2 receptor (B); control - 0.25\% DMSO, positive and negative controls was provided by the manufacturer of the kit; data are presented as \% of control $\pm \mathrm{SD}$; ${ }^{*} P \leq 0.001$; VD3 - 25-hydroxy Vitamin $\mathrm{D}_{3}$ at $25 \mu \mathrm{g} \mathrm{mL}{ }^{-1}$, Zn - zinc aspartate at $2.5 \mu \mathrm{g} \mathrm{mL}^{-1}$
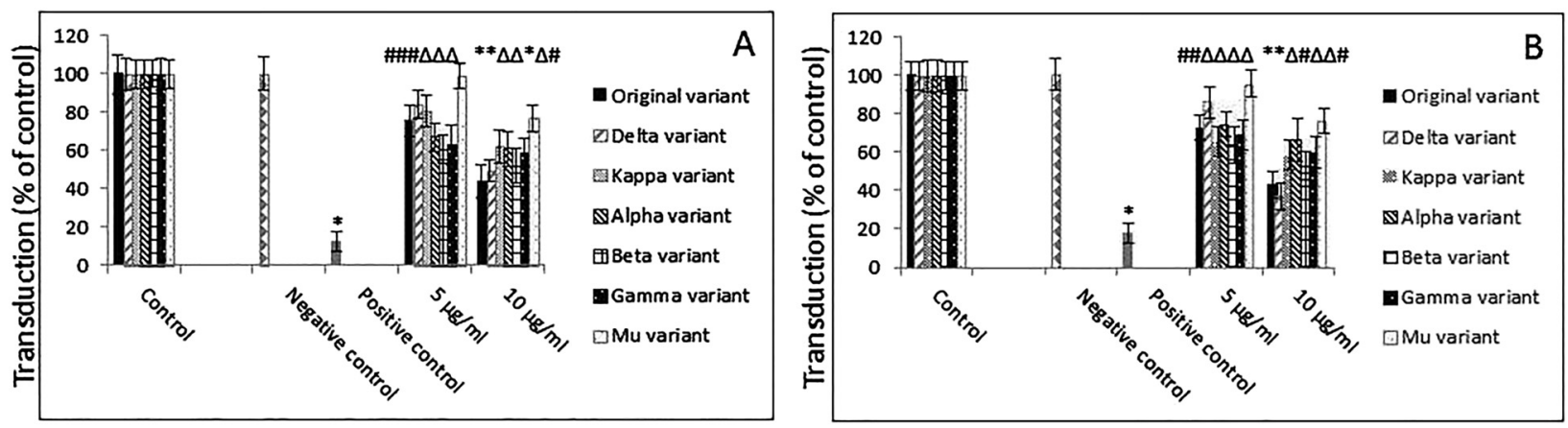

Fig. 2. Effect of MixV on SARS-CoV-2 eGFP-luciferase pseudo-typed variants entry. hACE2/A549 cells were inoculated with six different variants of SARS-CoV-2 pseudo-virions encapsulated with spike proteins and treated with MixV at designated concentrations either as a pre-treatment (A) or as a simultaneous exposure (B). Control - 0.05\% DMSO, negative control - pseudo-typed $\Delta$ G-luciferase (G ${ }^{\star} \Delta \mathrm{G}$ -

luciferase) rVSV, positive control - bald SARS-CoV-2 eGFP-luciferase pseudo-virions; \#P $\leq 0.05, \Delta P \leq 0.01,{ }^{*} P \leq 0.001$

Beta, Gamma, Delta, Kappa, and Mu variants for $1 \mathrm{~h}$ before their adding to A549/hACE2 cells, resulted in decreased viral entry by $39 \%, 48 \%$, and $42 \%, 57 \%, 51 \%, 39 \%$, and $24 \%$, respectively. Figure $2 \mathrm{~B}$ shows the effects of $\mathrm{MixV}$ on the test variants cellular entry inhibition when it was applied simultaneously with pseudo-typed virions and A549/hACE2 cells. In the presence of MixV at $10 \mu \mathrm{g} \mathrm{mL}^{-1}$ concentration, the cellular entry of Alpha virions was inhibited by $38 \%$, Beta by $48 \%$ and Gamma by $41 \%$. The inhibitory effect of the MixV on original SARS-CoV-2 virions entry was $57 \%$ and Delta, Kappa and $\mathrm{Mu}$ variants $64 \%, 42 \%$, and $24 \%$, respectively. The results presented on Fig. $3 \mathrm{~A}$ show that MixV applied at 5 and $10 \mu \mathrm{g} \mathrm{mL}^{-1}$ was not affecting viability of A549/hACE2 cells and the administration of vitamin D3 alone or with zinc did not have additional impact on their survival (Fig. 3B).

\section{Effect of MixV on viral RdRp polymerase}

In our study we also tested whether MixV acts beyond the binding steps of the SARS-CoV-2 infection process, by examining its effect on other important cellular mechanisms in viral infection, such as the activity of RdRp, which is essential for viral replication. As presented in Fig. 4A, enzymatic activity of recombinant SARS-CoV-2 RdRp was significantly inhibited by $53 \%$ in the presence of $\mathrm{MixV}$ at $10 \mu \mathrm{g} \mathrm{mL}{ }^{-1}$. Neither Vitamin D3 nor zinc enhanced this inhibitory effect. A similar inhibitory effect of $\mathrm{MixV}$ on RdRp activity was also observed when using the lysate of cells overexpressing RdRp protein (Fig. 4B).

\section{Effect of MixV on host cellular proteases}

It has been documented that various specific host cell proteases, including furin and cathepsin $\mathrm{L}$, are required to facilitate SARS-CoV-2 cellular entry by enzymatic "priming" spike proteins and viral egress. In our study, we applied cellfree assays to study direct effects of MixV on activity of these enzymes. As presented in Fig. 5A, we observed inhibition of the activity of furin by $12 \%$ and $34 \%$ with MixV applied at 5 and $10 \mu \mathrm{g} \mathrm{mL}^{-1}$, respectively. This inhibitory effect of MixV was further enhanced in the presence of vitamin D resulting 

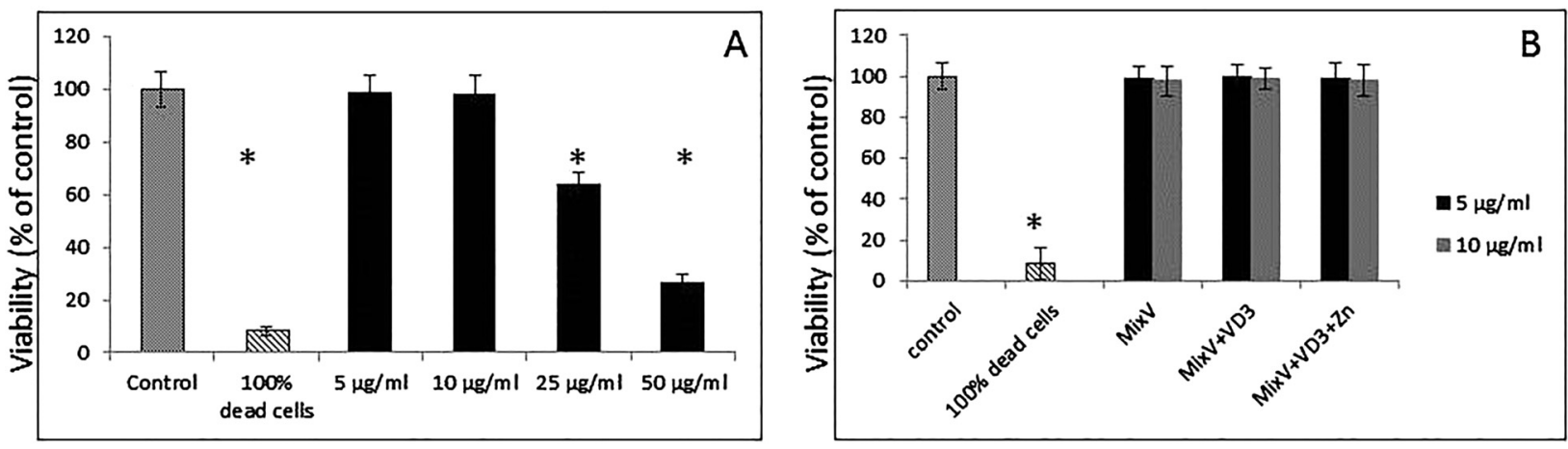

Fig. 3. Viability of human lung epithelial cells. Effects of MixV on survival of A549/hACE2 cells (A). Effects of MixV its combination with vitamin D3 and zinc on survival of A549/hACE2 cells (B). Viability of A549/hACE2 cells was assessed using MTT method as described in Experimental Procedures section; controls - 0.05\% DMSO; ${ }^{*} P \leq 0.001 \mathrm{VD} 3-25$-hydroxy Vitamin $\mathrm{D}_{3}$ at $25 \mu \mathrm{g} \mathrm{mL}{ }^{-1}, \mathrm{Zn}-\mathrm{zinc}$ aspartate at $2.5 \mu \mathrm{g} \mathrm{mL}-1$
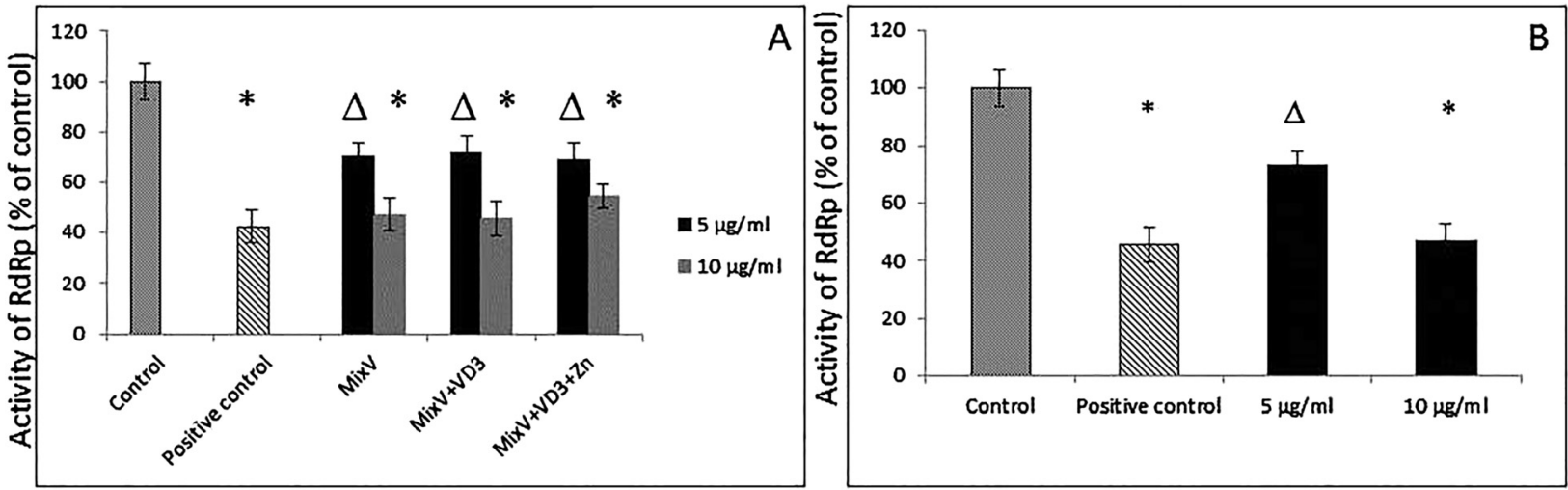

Fig. 4. Effect of MixV on viral RdRp. Effects of MixV alone (A) and in combination with vitamin D3 and zinc (B) on activity of SARS-CoV-2 RdRp. Purified recombinant RdRp enzyme in VeroE6 cells was incubated with MixV at designated concentrations for 15 min at RT. After application of reaction mix composed of NTPs and RNA template incubation was carry out for $2 \mathrm{~h}$ at $34^{\circ} \mathrm{C}$. Signal was measured in $10 \mathrm{~min}$ at extension/emission $=488 / 535 \mathrm{~nm}$ with spectrofluorometer. Control $-0.05 \% \mathrm{DMSO}$, positive control $-100 \mu \mathrm{g} \mathrm{mL} \mathrm{memdesivir}^{-1}$ $\Delta P \leq 0.01,{ }^{*} P \leq 0.001$; VD3 - 25-hydroxy Vitamin D3 at $25 \mu \mathrm{g} \mathrm{mL}{ }^{-1}, \mathrm{Zn}-$ zinc aspartate at $2.5 \mu \mathrm{g} \mathrm{mL}^{-1}$
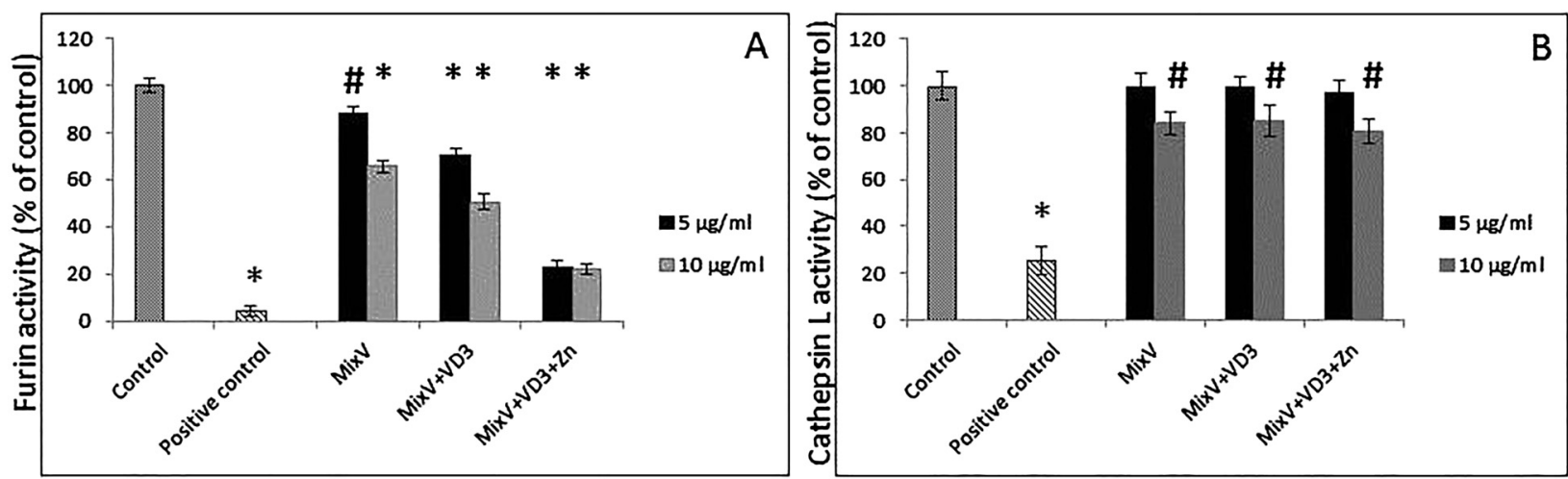

Fig. 5. Effect of MixV on cellular proteases. Effect of MixV on furin activity (A). Furin as a recombinant protein was incubated with MixV alone or in combination with vitamin $\mathrm{D}$ and zinc at indicated concentrations for $15 \mathrm{~min}$ followed by addition of fluorogenic Rh110 furin substrate, and incubation for $1 \mathrm{~h}$ at $22^{\circ} \mathrm{C}$. Effect of MixV on cathepsin $\mathrm{L}$ activity (B and C). Cathepsin $\mathrm{L}$ as a recombinant protein was incubated with $\mathrm{MixV}$ alone or in combination with vitamin $\mathrm{D}$ and zinc at indicated concentrations for $1 \mathrm{~h}$ at $22^{\circ} \mathrm{C}$ followed by the application of $10 \mu \mathrm{M}$ of fluorogenic substrate for $30 \mathrm{~min}$. Control $-0.05 \% \mathrm{DMSO}$, positive control $-25 \mu \mathrm{g} \mathrm{mL} \mathrm{E}^{-1} \mathrm{E}-64$; \# $P \leq 0.05$, ${ }^{\star} P \leq 0.001, \mathrm{VD} 3-25$-hydroxy Vitamin $\mathrm{D}_{3}$ at $25 \mu \mathrm{g} \mathrm{mL} \mathrm{m}^{-1}, \mathrm{Zn}-$ zinc aspartate at $2.5 \mu \mathrm{g} \mathrm{mL}^{-1}$ 
in $54 \%$ inhibition. A combination of MixV with vitamin D and zinc even further decreased furin activity by $78 \%$. As shown in Fig. 5B, the MixV, although mildly, also was effective in decreasing activity of cathepsin $\mathrm{L}$ involved in SARS-CoV-2 endosomal egress. In the presence of $10 \mu \mathrm{g}$ $\mathrm{mL}^{-1}$ MixV enzymatic activity of cathepsin $\mathrm{L}$ was reduced by $14 \%$, and addition of vitamin D3 did not have a significant effect on cathepsin L inhibition.

\section{DISCUSSION}

Our study represents a new comprehensive approach to COVID-19 with its aim at controlling not one but several cellular mechanisms associated with SARS-CoV-2 infectivity at once. Our results show that a defined combination of active plant components and selected micronutrients (MixV) can significantly affect critical steps required for cellular infectivity of the original SARS-CoV-2 strain and its mutated forms Alpha, Beta, Gamma, Delta, Kappa, and $\mathrm{Mu}$, by inhibiting viral attachment to cellular ACE2 receptors, decreasing availability of these receptors on human lung cells, and decreasing activity of viral RdRp necessary for viral replication. In addition, these natural compounds interfered with cellular entry of the virions by decreasing activity of important enzymes such as furin and cathepsin L (see Fig. 6).

These findings further expand on our earlier study using SARS-CoV-2 virion particles, which identified core ingredients in this combination, which were effective in inhibiting viral binding to hACE2 receptor and decreasing expression of ACE2 receptors on human small alveolar epithelial cells [21]. Taking into account immediate availability and high safety profile of these natural compounds, their application as preventive measures, e.g. as an adjunct to vaccines and therapies of COVID, is plausible.

While all tested nutrient combinations (A, B, C, D and E) were effective in blocking RBD binding to ACE2 by about $50 \%$, the MixV demonstrated the highest, $90 \%$ inhibition of viral binding. This would indicate that synergistic or at least additive effect could play a role here, not excluding other, e.g., allotropic, interactions between the compounds of MixV and RBD/ACE2.

Our study investigated inhibitory effects of MixV on cellular internalization of both SARS-CoV-2 virions and its mutated forms using different pattern of exposure of these virions to MixV and human lung cells. As such, we incubated test virions with $\mathrm{MixV}$ for $1 \mathrm{~h}$ before their exposure to the cells and combined MixV with virions and cells simultaneously. The results indicate that maximum inhibition of cellular transduction by these virions can be obtained when all of these elements interacted at the same time. This would imply that this mixture affects metabolic aspects of cell-virions interactions rather than acts on the virus itself. Although its efficacy in inhibiting viral internalization was not virus specific, MixV was nevertheless most effective in inhibiting the original SARS-CoV-2 and Delta variants compared to other mutated forms.

In addition to the inhibitory effect of MixV on cellular attachment and entry of SARS-CoV-2 virions, we also observed that MixV affected cellular mechanisms involved in endosomal egress and multiplication of the virus by decreasing activity of enzymes involved in viral cellular processing. Among the proteolytic enzymes involved in these processes, the activity of cathepsin L and furin has been shown to be important for pathogenicity of SARSCoV-2 [22, 23]. It also has been shown that furin action towards the SARS-CoV-1 spike protein is necessary for the fusion of virions with host membranes, without directly affecting viral infectivity [24]. It appears that effective control and treatment of SARS-CoV-2 infection might necessitate simultaneous inhibition of several proteases to effectively obstruct these pathological conversions.

Here we have shown that, in addition to impairing viral binding to hACE2 overexpressing lung epithelial cells, the $\mathrm{MixV}$ decreased activity of membrane protease furin and endosomal cathepsin L. The reduction of the activity of these enzymes was observed at non-toxic MixV concentrations. This effect is significant, as the lack of the additional furin cleavage site on the SARS-CoV-1 spike protein has a substantial influence on its infectivity [25].

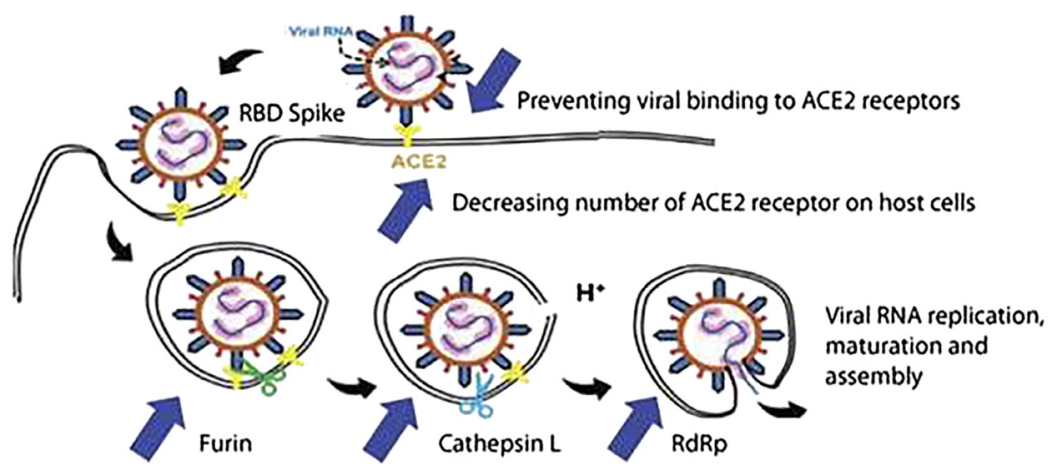

Inhibiting enzymes involved in viral cellular processing : Furin, Cathepsin L, RdRp

Fig. 6. Schematic representation of the effects of MixV on key cellular processes associated with SARS-CoV-2 infectivity 
In addition to SARS-CoV-2 infection, the potential signal link between spike protein, furin, and ACE2 has been implied in the occurrence of adverse cardiovascular events [26]. Since these enzymes are also involved in various biochemical pathways, a lack of complete inhibition at the concentrations of MixV used in the study may be beneficial. We observed that vitamin D3 and zinc had additional effect on lowering enzymatic activity of furin, but not cathepsin L. Finally, we also recorded a substantial inhibition of activity of viral RdRp at these concentrations, with its consequences at reduced replication rate of the virus.

Based on this study and our earlier findings [18, 19, 27], this combination of plant-derived compounds and micronutrients may constitute a new anti-SARS-CoV-2 strategy by simultaneously affecting multiple aspects of viral life cycle, including viral entry and replication. This strategy was also implemented in our earlier studies, including those of human influenza H1N1, bird flu H1N5, and others, which were based on selecting natural components that simultaneously affect key pathology mechanisms across a wide spectrum of infective agents [28-31].

Our study implies that a simultaneous control of key steps of the SARS-CoV-2 infectivity by a definite combination of plant-derived and biologically active compounds can be effective in addressing complex pathologies, such as involved in this viral infection. Taken together, with the recently established clinical evidence that vitamin $\mathrm{C}$ infusions can successfully combat COVID-19 even at advanced stages [32], phyto-compounds through their pleiotropic biological effects could represent a new approach against SARS-CoV-2 and its mutants.

Funding: This research was supported by funding from the non-profit Dr. Rath Health Foundation belonging to Stichting Administratiekantoor Dr. Rath Holding, NL.

Author contributions: A.G. conceived, designed, and performed the experiments, analyzed data, reviewed the paper, and had primary responsibility for final content; V.I. and S.I. designed and performed the experiments, analyzed data, reviewed the paper, and had primary responsibility for final content. A.N. and M.R. supervised, validated, wrote the paper, and had primary responsibility for final content. All authors had full access to all data in the study, they have read and approved the final manuscript and take responsibility for the integrity of the data and the accuracy of the data analysis.

Conflict of interest: Dr. Rath and Dr. Niedzwiecki are members of the non-profit Dr. Rath Health Foundation but do not receive any financial revenues from it. All authors declare no potential conflict of interest with respect to the research, authorship, and/or publication of this article.

Data availability statement: All data generated or analyzed during this study are included in this published article.

\section{ACKNOWLEDGMENT}

The authors thank Dr. Bilwa Bhanap, Vyoma Bhanap, Waldemar Sumera, and Cathy Flowers for their valued contribution added to this manuscript.

\section{REFERENCES}

1. Chakraborty I, Maity P. COVID-19 outbreak: migration, effects on society, global environment and prevention. Sci Total Environ 2020;728:138882. https://doi.org/10.1016/j.scitotenv.2020.138882.

2. WHO coronavirus disease (COVID-19) dashboard. https://www. who.int/publications/m/item/weekly-epidemiological-update-oncovid-19-31-august-2021.

3. Tracking SARS-CoV-2 variants. https:/www.who.int/en/activities/ tracking-SARS-CoV-2-variants/.

4. Andreano E, Piccini G, Licastro D, Casalino L, Johnson NV, Paciello I, et al. SARS-CoV-2 escape from a highly neutralizing COVID-19 convalescent plasma. Proc Natl Acad Sci USA 2021; 118(36):e2103154118. https://doi.org/10.1073/pnas.2103154118.

5. Zhang L, Cui Z, Li Q, Wang B, Yu Y, Wu J, et al. Ten emerging SARS-CoV-2 spike variants exhibit variable infectivity, animal tropism, and antibody neutralization. Commun Biol 2021;4(1): 1196. https://doi.org/10.1038/s42003-021-02728-4.

6. Collier DA, Marco AD, Ferreira IATM, Meng B, Datir RP, Walls AC, et al. Sensitivity of SARS-CoV-2 B.1.1.7 to mRNA vaccineelicited antibodies. Nature 2021;593:136-41. https://doi.org/10. 1038/s41586-021-03412-7.

7. Dyson L, Hill EM, Moore S, Curran-Sebastian J, Tildesley MJ, Lythgoe $\mathrm{KA}$, et al. Possible future waves of SARS-CoV-2 infection generated by variants of concern with a range of characteristics. Nat Commun 2021;12(1):5730. https://doi.org/10.1038/s41467-021-25915-7.

8. Li, F. Structure, function, and evolution of coronavirus spike proteins. Annu Rev Virol 2016;3:237-61. https://doi.org/10.1146/ annurev-virology-110615-042301.

9. Du L, He Y, Zhou Y, Liu S, Zheng B J, Jiang S. The spike protein of SARS-CoV-a target for vaccine and therapeutic development. Nat Rev Microbiol 2009;7:226-36. https://doi.org/10.1038/ nrmicro2090.

10. Du L, Yang Y, Zhou Y, Lu L, Li F, Jiang S. MERS-CoV spike protein: a key target for antivirals. Expert Opin Ther Targets 2017; 21(2):131-43. https://doi.org/10.1080/14728222.2017.1271415.

11. Fehr AR, Perlman S. Coronaviruses: an overview of their replication and pathogenesis. Methods Mol Biol 2015;1282:1-23. https://oi. org/10.1007/978-1-4939-2438-7_1.

12. Glowacka I, Bertram S, Müller MA, Allen P, Soilleux E, Pfefferle S, et al. Evidence that TMPRSS2 activates the severe acute respiratory syndrome coronavirus spike protein for membrane fusion and reduces viral control by the humoral immune response. J Virol 2011; 85(9):4122-34.

13. Simmons G, Gosalia DN, Rennekamp AJ, Reeves JD, Diamond SL, Bates P. Inhibitors of cathepsin L prevent severe acute respiratory syndrome coronavirus entry. Proc Natl Acad Sci 2005;102(33): 11876-81.

14. Zhang D, Hamdoun S, Chen R, Yang L, Ip CK, Qu Y, et al. Identification of natural compounds as SARS-CoV-2 entry 
inhibitors by molecular docking-based virtual screening with biolayer interferometry. Pharmacol Res 2021;172:105820. https://oi. org/10.1016/j.phrs.2021.105820.

15. Muchtaridi M, Fauzi M, Khairul Ikram NK, Mohd Gazzali A, Wahab HA. Natural flavonoids as potential angiotensin-converting enzyme 2 inhibitors for anti-SARS-CoV-2. Molecules 2020;25(17): 3980. https://doi.org/10.3390/molecules25173980.

16. Gopinath K, Jokinen EM, Kurkinen ST, Pentikäinen OT. Screening of natural products targeting SARS-CoV-2-ACE2 receptor interface -A MixMD based HTVS pipeline. Front Chem 2020;8:589769. https://doi.org/10.3389/fchem.2020.589769.

17. Yang LJ, Chen RH, Hamdoun S, Coghi P, Ng JPL, Zhang DW, et al. Corilagin prevents SARS-CoV-2 infection by targeting RBD-ACE2 binding. Phytomedicine 2021;87:153591. https://doi.org/10.1016/j. phymed.2021.153591.

18. Goc A, Ivanov V, Ivanova S, Chatterjee M, Rath M, Niedzwiecki A. Simultaneous inhibition of SARS-CoV-2 infectivity by a specific combination of plant-derived compounds. Eur J Bio Biotech 2021; 2(5):24-33. https://doi.org/10.24018/ejbio.2021.2.5.258.

19. Goc A, Sumera W, Rath M, Niedzwiecki A. Phenolic compounds disrupt spike-mediated receptor-binding and entry of SARS-CoV-2 pseudo-virions, PLOS ONE 2021;16(6):e0253489. https://doi.org/ 10.1371/journal.pone.0253489.

20. Goc A, Niedzwiecki A, Rath M. Polyunsaturated $\omega-3$ fatty acids inhibit ACE2-controlled SARS-CoV-2 binding and cellular entry. Sci Rep 2021;11:5207. https://doi.org/10.1038/s41598-021-84850-1.

21. Ivanov V, Goc A, Ivanova S, Niedzwiecki A, Rath M. Inhibition of ACE2 expression by Ascorbic acid alone and its combination with other natural compounds. Infect Dis Res Trmt (Auckl) 2021;14:1-7. https://doi.org/10.1177/1178633721994605.

22. Liu T, Luo S, Libby P, Shi GP. Cathepsin L-selective inhibitors: a potentially promising treatment for COVID-19 patients. Pharmacol Ther 2020;213:107587. https://doi.org/10.1016/j.pharmthera.2020. 107587.

23. Tian S, Huang Q, Fang Y, Wu J. Furin DB: A database of 20-residue furin cleavage site motifs, substrates and their associated drugs. Int J Mol Sci 2011;12(2):1060-5. https://doi.org/10.3390/ijms12021060.

24. Follis KE, York J, Nunberg JH. Furin cleavage of the SARS coronavirus spike glycoprotein enhances cell-cell fusion but does not affect virion entry. Virology 2006;350(2):358-69. https://doi.org/10. 1016/j.virol.2006.02.003.

25. Johnson BA, Xie X, Kumari BK, Lokugamage G, Muruato A, Zou J, et al. Furin cleavage site is key to SARS-CoV-2 pathogenesis. bioRxiv 2020:268854. https://doi.org/10.1101/2020.08.26.268854 Preprint.

26. Ming Y, Qiang L. Involvement of spike protein, furin, and ACE2 in SARS-CoV-2-related cardiovascular complications. SN Compr Clin Med 2020;2:1103-8. https://doi.org/10.1007/s42399-020-00400-2.

27. Ivanov V, Ivanova S, Niedzwiecki A, Rath M. Effective and safe global public health strategy to fight the COVID-19 pandemic: specific micronutrient combination inhibits Coronavirus cell-entry receptor (ACE2) expression. J Cell Med Nat Health 2020. https:// jcmnh.org/effective-and-safe-global-public-health-strategy-tofight-the-covid-19-pandemic-specific-micronutrient-compositioninhibits-coronavirus-cell-entry-receptor-ace2-expression/.

28. Barbour EK, Rayya EG, Houssam, AS, El-Hakim RG, Niedzwiecki A, Nour AMA, et al. Alleviation of histopathologic effects of avian influenza virus by a specific nutrient synergy. Int J Appl Res Vet Med 2007;5(1):9-16.

29. Jariwalla RJ, Gangapurkar B, Pandit A, Kalinovsky T, Niedzwiecki A, Rath M. Micronutrient cooperation in suppression of HIV production in chronically and latently infected cells. Mol Med Rep 2010;3(3):377-85. https://doi.org/10.3892/mmr_00000268.

30. Deryabin PG, Lvov DK, Botikov AG, Ivanov V, Kalinovsky T, Niedzwiecki A, et al. Effects of a nutrient mixture on infectious properties of the highly pathogenic strain of avian influenza virus A/H5N1. Biofactors 2008;33(2):85-97. https://doi.org/10.1002/biof. 5520330201.

31. Jariwalla RJ, Roomi MW, Gangapurkar B, Kalinovsky T, Niedzwiecki A, Rath M. Suppression of influenza A virus nuclear antigen production and neuraminidase activity by a nutrient mixture containing ascorbic acid, green tea extract and amino acids. Biofactors 2001;31(1):1-15. https://doi.org/10.1002/biof. 5520310101.

32. Zhang J, Rao X, Li Y, Zhu Y, Liu F, Guo G, et al. High dose vitamin C infusion for the treatment of critically ill COVID-19. Ann Intensive Care 2021;11(1):5. https://doi.org/10.1186/s13613-02000792-3. 